\title{
PHYSICIAN-PATIENT COMMUNICATION ABOUT THE USE OF DIETARY SUPPLEMENTS: RESULTS OF A PILOT STUDY
}

\author{
Zh. Tsokeva ${ }^{*}$, K. Sokolova ${ }^{1}$, S. Dimitrova ${ }^{2}$, M. Valcheva ${ }^{3}$ \\ ${ }^{1}$ Department of Pharmacology and Clinical Pharmacology, Faculty of Medicine, Traкia University, \\ Stara Zagora, Bulgaria \\ ${ }^{2}$ Department of Social Medicine and Health Care Management, Faculty of Medicine, \\ Тгакіа University, Stara Zagora, Bulgaria \\ ${ }^{3}$ Student in Medicine, Faculty of Medicine, Traкia University, Stara Zagora, Bulgaria
}

\begin{abstract}
The growing use of dietary supplements, often combined with conventional drugs, creates a possibility of adverse reactions and interactions and asks for their safe application. The majority of patients do not disclose the use of dietary supplements to doctors; physicians are not always informed about the adoption of supplements and are often reluctant to initiate discussion on this topic. This lack of physician-patient comunication leads to an increased risk of the dietary supplements use.

PURPOSE: To establish some of physician-patient communication problems on the use of dietary supplements.

METHODS: This is a pilot study on the use of dietary supplements among the population of the town Stara Zagora. The pilot study was conducted by self- administrated questionnaire on people aged 19 to 59 years $(n=24)$.

RESULTS: The opinion of $45.8 \%$ of all respondents in this pilot study is that when visiting doctors they have never been asked about the use of dietary supplements.78.8\% of users of dietary supplements in the study did not tend to spontaneously share with their physicians that they accept food supplements.

CONCLUSION: The low level of communication on the use of dietary supplements highlights the need for a new type of physician-patient relationships in order to reduce the risks associated with the use of dietary supplements.
\end{abstract}

Key words: food supplements, level of communication

\section{INTRODUCTION}

Over the last few decades, higher interest and increasing use of dietary suppplements (DS) has been observed worldwide. (1-3)

According to the European Directive 2002/46/EU, 'food (dietary) supplements' refers to food stuffs whose purpose is to supplement the normal diet and which are concentrated sources of nutrients or other substances with nutritional or physiological effect, alone or in combination, and which are

\footnotetext{
*Correspondence to: Zhivka Tsokeva, Department of Pharmacology and Clinical Pharmacology, Faculty of Medicine, Trakia University, Stara Zagora, Bulgaria, Armeiska 11 St., 6000 Stara Zagora, Bulgaria, Tel.: +3594266244 E-mai address: jic1973@hotmail.com
}

marketed in dose form, such as capsules, pastilles, tablets, pills and other similar forms, sachets of powder, ampoules of liquids, drop dispensing bottles, and other similar forms of liquids and powders, all designed to be taken in measured small unit quantities. (4) Similar is the definition of DS given by DSHEA in the USA. (5)

In analyses of the socio-demographic characteristics of consumers, a general profile emerges, whereby the representatives of the female sex, people belonging to the white race, people with higher education levels and higher incomes are more likely to use DS. (3)

Among one group of users, the main reason for taking HD is "maintaining the overall health 
and well-being“. (6-8) This group of people aspires to a healthy lifestyle, including good diet, regular exercise, healthy weight maintenance and tobacco avoidance. They define their health as very good or excellent and, in this sense the use of DS is an expression of the desire to remain healthy and only one component of efforts to lead a healthy lifestyle. (8) Among another group of patients, DS intake is associated with the presence of other, more common chronic diseases, so that in these cases DS may be in the role of alternative or complementary conventional therapy agents. The use of DS as an alternative means of treatment can lead to the delay of appropriate, effective conventional therapies and threaten the health of patients. (9) The use of DS as complementary care is also unsafe, despite consumers' belief that these products are harmless due to their natural origin. (10) With increasing use, evidence has accumulated to suggest that the use of DS, especially plantbased ones, is associated with variedly severe adverse reactions, in turn related to the presence of multiple active components. (1114) A small portion of patients are aware of the fact that DS are not subject to the same strict regulation as conventional drugs, often lack evidence of efficacy and safety, and in many cases lack quality guarantees of these products. In recent years, several studies have been devoted to clarifying the weaknesses in the regulation of supplements and the possibility of allowing adulteration, substitution, contamination, misidentification, lack of standardization, incorrect preparation and/or dosage and inappropriate labeling. $(12,15)$ In patients with chronic diseases who receive one or more prescribed medications, the risk of DS use is also associated with the possibility of interactions between DS and other received medicines, many of which have already been documented. $(16,17)$

In addition to those risk factors, frequent use of DS occurs by personal initiative and choice, rather than by recommendation of physicians and other health care professionals. (6) Majority of patients do not inform their physicians about intake such products. "Selfprescription" of DS, concomitant use with drugs, and failure to disclose DS intake to doctors all increase the risk of health problems and raise concern for patients. Safe integration of DS in modern therapeutic regimens requires open doctor-patient discussion to clarify the use or intention to use DS and the benefits and risks associated with these products, and to support informed decision- making by the patient.

\section{PURPOSE}

The purpose of this study is to establish some problems of physician-patient communication related to the use of DS.

\section{MATERIAL AND METHODS}

The study represents some of the results from a pilot study on the use of DS among the population of town Stara Zagora conducted between July and August 2014 with the participation of 24 people (10 men and 14 women), aged 19- 59 years. An individual selfadministrated questionnaire was used to gather the information about DS intake within the past year, observing the principles of anonymity and voluntariness. A part of questions assessed some communication patterns related to DS use: respondents' disclosure of DS use, reasons for nondisclosure and frequency of physicians' interest on the use of DS. Descriptive statistics was employed to examine the data. Data analysis was conducted using SPSS (version 13.0).

\section{RESULTS AND DISCUSSION}

$37.5 \%(n=9)$ of participants in the present study were taking one or more DS during the past year. According to European Prospective Investigation into Cancer (EPIC) study there are marked differences in the use of DS in Europe with a strong North-South gradient among ten European countries participating in the study: the highest use of DS was found in Scandinavia and the lowest-in the Mediterranean. These geographical differences in DS use could be explained by cultural and behavior differences between European countries. (1) Beside the data from EPIC the level of use of DS in present study was higher in comparison with Greece, Spain and Italy and lower in comparison with Norway and Denmark. The use of DS appears to be at an intermediate level close to that in France and in UK men:

Traditionally higher is the use of DS in the USA. According to a pooled analysis of data from National Health And Nutrition Examination Survey (NHANES) more than half of adults in the USA accept DS and this level of use remains stable from 2000 years until today. (8) In our data there are no comprehensive studies on the use of DS in Bulgaria. 
TSOKEVA ZH., et al.

$55.6 \%$ of users of DS in the study stated that received DS have not been recommended by physician or other health care professionals. Our findings are consistent with prior studies establishing that majority of people accept DS without medical recommendation. $(6,9,18$, 19) Additionally patients often do not disclose their DS use to the health care providers. In the present study, $78.8 \%$ of users of DS did not tend to spontaneously share with their physicians that accept DS. Physician-patient communication about DS is the object of many studies. Some of them are on hospitalized patients or address physician-patient communication about complementary and alternative medicine (CAM) in general and are not specifically focused on communication about DS use. Despite the differences in the design many studies highlight that less than $30 \%$ of patients who take DS disclose this to their physicians. (20-24) Broader literature suggests that disclosure about DS use is a function of both patient and physician characteristics. (25-28).Various demographic, socioeconomic and psychological factors can influence physician-patient communication about DS use and correlate with the rate of disclosure. $(23,29,30)$ Because of the small number of participants in the pilot study a comparative analysis of the impact of such factors on the disclosure rate was not carried out.

A variety of reasons, including anticipating physicians ' disinterest, anticipating a negative response from physicians, or assuming that physicians lacked sufficient knowledge and other are discussed in connection with the low level of patients' disclose regarding alternative means of treatment. (31-33)

Among respondents not sharing their DS use with physicians in our study $42.9 \%$ state as the leading reason for this ,there is not enough time during the visits". The remaining part of respondents indicate that failure to disclose was due to "doctors do not ask“ $(28.6 \%)$ or because of personal conviction that ,it is not necessary to inform physicians about DS intake" (28.6\%). Physicians' disinterest and patients ' belief that there is no need to inform health care professionals appear to be leading reasons for the low rate of disclosure in prior studies of DS use. In another study a significant proportion of patients indicate time restictions during the visits as a third main reason for non-disclosure. $(18,24,33,34)$ The fear of disapproval by physicians was not listed as a reason for non-disclosure about DS intake in any of the respondents, which is in compliance with results of other studies. (21, 35) According to surveys most physicians have an open attitude toward alternative therapies but are limited with regards to their ability to discuss them due to an inadequate knowledge base. $(36,37)$

Inquaring all respondents in the study „During your visits does your doctor ask you about DS intake?" $45.8 \%$ of participants answered „never", 33.3\%-"very rarely" and 20.8\%"rarely".

Some other studies suggest that the majority of patients were not asked whether they accept DS during hospitalization or medical visits. $(24,34,38,39)$ Physicians do not commonly ask patients about their DS use, and patients may feel uncomfortable to discuss it. Many patients might not volunteer share intake of DS to their physicians, but they are willing to engage in discussion if asked. $(22,40,41) \mathrm{A}$ limited number of studies consider the communication problems about DS use from physicians" perspective. (30) Physicians generally avoid provoke discussions about DS use possibly because of the lack of knowledge. $(41,42)$ Insufficiency of knowledge, difficulties in obtaining valuable information, and the fact that DS are incongruous with the regulation of medicines can justify the reluctance of physicians to discuss such matters with their patients. It is unrealistic to expect from physicians to convey complete information about DS and to seek information about obscure supplements during timeconstrained office visits. However, regardless of their level of knowledge about an individual supplement or DS at all, physicians should consider even more general information. Physicians must be cognizant of the potential adverse reactions and interactions of DS with various prescribed drugs. They must be vigilant on the causal relationship between the use of DS and the occurrence of adverse events. Many patients falsely believe that DS are subject to the same rigorous control as drugs. Touching upon regulatory issues physicians can help their patients to make an informed choice about DS use. $(18,32)$

\section{CONCLUSION}

The present study is not intended as a commentary on the benefits or risks of DS or on the potential role of these products in patient care. Outstanding widespread use of DS is a sufficient reason for a more thorough 
analysis of the problems associated with DS use. Albeit preliminary, our results indicate a gap of physician-patient communication about DS intake. The weakness in legislation and cumbersome regulatory changes regarding DS highlight the importance of building a new type of relationship between patients and physician as a factor in reducing the risks associated with the use of DS. Healthcare professionals need to ask patients about DS intake. Patients need to be informed that sharing DS intake may be needful in safeguarding their health.

\section{LIMITATIONS OF THE STUDY}

The small sample size limits the statistical analysis of results and their generalizability. The study considered only patients" perspective. Most studies on patient-physician communication are on hospitalized patients and patients with chronic diseases, which hinder the comparability of results. This study is a pilot and our results are preliminary. Further investigation is needed to increase sample size for a thorough analysis of both physician-patient communication and other problems related to the use of DS.

\section{REFERENCES}

1. Skeie G, Braaten T, Hjartaker A, Lentjes M, Use of dietary supplements in the European Prospective Investigation into Cancer and Nutrition calibration study. Eur J Clin Nutr, 63: 226-238, 2009.

2. Bailey RL, Gahche JJ, Lentino CV, et al, Dietary supplement use in the United States, 2003-2006. J Nutr, 141(2): 261-266, 2011.

3. Dickinson A, Blatman J, El-Dash N, Franco JC. Consumer usage and reasons for using dietary supplement: report of series of surveys. J Am Coll Nutr, 33(2): 176-82, 2014.

4. European Directive 2002/46 / EC https://www.fsai.ie/uploadedFiles/Dir\%2020 02.46\%20EC\%282\%29.pdf)"

5. FDA.US Food and Drug Administration. Regulatory Information.Dietary Supplement Health and Education Act of 1994 http://www.fda.gov/RegulatoryInformation/ Legislation/FederalFoodDrugandCosmeticA ctFDCAct/SignificantAmendmentstotheFDC Act/ucm148003.htm\#sec3

6. Bailey RL, Gahche JJ, Miller PE, Thomas PR, Dwyer JT, Why US Adults Use Dietary Supplements. JAMA Intern Med,173(5):355361, 2013.

7. Rovira MA, Grau M, Castañer O, Covas MI, Schröder H, REGICOR Investigators Dietary supplement use and health-related behaviors in a mediterranean population. $J$ Nutr Educ Behav, 45(5): 386-391, 2013.

8. Dickinson A, MacKay D, Health habits and other characteristics of dietary supplement users: a review. Nut J, 13:14, 2014.http://www.ncbi.nlm.nih.gov/pubmed/2 4499096

9. Eichhorn T, Greten H J and Efferth T, Selfmedication with nutritional supplements and herbal over-the-counter products. Nat. Prod. Bioprospect, 1: 62-70, 2011.

10. Colalto $\mathrm{C}$, Unpredictable adverse reactions to herbal products. J Drug Metab Toxicol, 3:2,2012. Available at http://www.omicsonline.org/21577609/2157-7609-

11. Palmer ME, Haller C, McKinney PE, KleinSchwartz W, Tschirgi A, Smolinske SC, Woolf A, Sprague BM, Ko R, Everson G, Nelson LS, Dodd-Butera T, Bartlett WD, Landzberg BR, Adverse events associated with dietary supplements: an observational study. Lancet, 361 (9352): 101-6, 2003.

12. Pittler MH, Ernst E, Review Systematic review: hepatotoxic events associated with herbal medicinal products. Aliment Pharmacol Ther, 18(5): 451-71, 2003.

13. Timbo BB, Ross MP, McCarthy PV, Lin CT, Dietary supplements in a national survey: Prevalence of use and reports of adverse events. J Am Diet Assoc, 106(12): 1966-74, 2006.

14. Haller C, Kearney $\mathrm{T}$, Bent $\mathrm{S}$, Ko R, Benowitz N, Olson, K, Dietary supplement adverse events: report of a one-year poison center surveillance project. $J$ Med Toxicol, 4(2): 84-92, 2008.

15. Koh HL, Woo SO, Chinese proprietary medicine in Singapore: Regulatory control of toxic heavy metals and undeclared drugs. Drug Saf, 23:351-362, 2000.

16. Tsai H.-H, Lin H.-W, Pickard S.A, Tsai H.Y, Mahady G.B, Evaluation of documented drug interactions and contraindications associated with herbs and dietary supplements: a systematic literature review. Int J Clin Pract, 66(11): 1056-78, 2012.

17. Posadzki P, Watson LK, Alotaibi A, Ernst E, Prevalence of use of complementary and alternative medicine (CAM) by patients/consumers in the UK: systematic review of surveys. Clin Med, 13(2): 126-31, 2013.

18. Marinac JS, Buchinger CL, Godfray LA, Wooten JM, Sun C, Willsie SK, Herbal products and dietarysupplements: a survay of use, attitudes, and knoweledge among older adults. JAOA, 107 (1):13-19, 2007. 
19. Denham BE, Dietary supplementsregulatory issues and implications for public health. JAMA, 306(4):428-9, 2011.

20. Eisenberg DM, Davis RB, Ettner SL, et al.,Trends in alternative medicine use in the United States, 1990-1197: results of a follow-up national survey. JAMA, 280:15691575, 1998.

21. Robinson A, McGrail MR, Disclosure of CAM use to medical practitioners: a review of qualitive and quantitive studies. Complement Ther Med, 12 (2-3): 90-8, 2004.

22. Gardiner P, Graham RE, Legedza AT, Eisenberg DM, Phillips RS, Factor associated with dietary supplement use among prescription medication users FREE. Arch Intern Med, 166 (18): 1986-1974, 2006.

23. Kennedy J, Wang CC, Wu CH. Patient disclosure about herb and supplement use among adults in the US. eCAM, 5:451-456, 2008.

24. Young LA, Faurot KR, Gazlord SA, Use and communication about dietary supplement use among hospitaliyed patients. J Gen Intern Med, 24 (3): 366-369, 2009.

25. Wynia MK, Eisenberg DM, Wilson IB. Physician-patient communication about complementary and alternative medical therapies: A survey of physicians caring for patients with human immunodeficiency virus infection. J Altern Complement Med, 5:44756, 1999.

26. Silverstein DD, Spiegel AD, Are physicians aware of the risks of alternative medicine? $J$ Community Health, 26: 159-74, 2001.

27. Tasaki K, Maskarinec G, Shumay DM, Tatsumura Y, Kakai H, Communication between physicians and cancer patients about complementary and alternative medicine: Exploring patients' perspectives. Psychooncology, 11: 212-20,2002.

28. Giveon SM, Liberman N, Klang S, Kahan E. A survey of primary care physicians' perceptions of their patients' use of complementary medicine. Complement Ther Med, 11:254-60, 2003.

29. Mehta DH, Gardiner PM, Phillips RS, McCarthy EP, Herbal and dietary supplement disclosure to health care providers by individuals with chronic conditions. J Altern Complement Med, 14 (10): 1263-9, 2008.

30. Ben-Arye E, Frenkel M, Margalit R. Approaching complementary and alternative medicine use in patients with cancer: questions and challenges. I Ambul Care Manage, 27: 53-62, 2004.

31. Adler SR, Fosket JR, Disclosing complementary and alternative medicine use in the medical encounter: a qualitative study
TSOKEVA ZH., et al. in women with breast cancer. J FamPract, 48: 453-458, 1999.

32. Ashar BH, Miller RG, Pichard $\mathrm{CP}$ et al, Patients' understanding of the regulation of dietary supplements. J Community Health,33: 22-30, 2008.

33. NCCAM, \& AARP. (2010). Complementary and Alternative Medicine: What People Aged 50 and Older Discuss With Their Health Care Providers. Consumer Survey Report, (Vol. 2011), 2011.

34. Haller CA, We should always ask our patients about unconventional treatments. West J Med, 175 (3):164, 2001.

35. Eisenberg DM, Kessler RC, Van Rompay MI, Kaptchuk TJ, Wilkey SA, Appel S, Davis RB, Perceptions about complementary therapies relative to conventional therapies among adults who use both: results from a national survey. Ann Intern Med, 135(5): 344-51, 2001.

36. Astin JA, Marie A, Pelletier KR, et al. A review of the incorporation of complementary and alternative medicine by mainstream physicians. Arch Intern Med, 158: 2303- 2310, 1998.

37. Crock RD, Jarjoura D, Polen A, Rutecki GW, Confronting the communication gap between conventional and alternative medicine: A survey of physicians' attitudes. Altern Ther Health Med, 5: 61-66, 1999.

38. Goldstein LH, Elias M, Ron-Avraham G, Biniaurishvili BZ, Madjar M, Kamargash I, Braunstein R, Berkovitch M, Golik A, Consumption of herbal remedies and dietary supplements amongst patients hospitalized in medical wards. Br J Clin Pharmacol, 64(3): 373-80, 2007.

39. Tarn DM, Paterniti DA, Good JS, Coulter ID, Galliher JM, Kravitz RL, Karlamangla AS, Wenger NS, Physician-patient communication about dietary supplements. Patient Education and Counseling, 91: 287294, 2013.

40. Bouwmeester CJ, Surveying physicians' attitudes about herbal supplements, resources, and pharmacy consultations. $J$ Pharm Technol, 21: 247-53, 2005.

41. Kemper KJ, Amata-Kynvi A, Dvorkin L, Whelan JS, Woolf A, Samuels RC, Hibberd $\mathrm{P}$, Herbs and other dietary supplements: healthcare professionals' knowledge, attitudes, and practices.Altern Ther Health Med, 9 (3): 42-9, 2003.

42. Corbin WL, Shapiro H, Physicians want education about complementary and alternative medicine to enhance communication with their patients. Arch Intern Med, 162 (10): 1176-1181, 2002. 
TSOKEVA ZH., et al. 